\title{
Inno-duction: is there a logical formula for breaking new ground?
}

\section{Introduction}

In dealing with innovation, naming it and hoping for it to be clear and distinct as to what is being referred to will not suffice. Figuring out in some way what innovation is may on its own assist any researcher or manager in discerning that whatever pre-set arrangements or dogmas she/he comes across along her/his career are not holy or unchangeable, but rather potential sources of input that could be developed or exploited in more or less intelligent, innovative or even profitable ways.

How could it be better for researchers to grasp what innovation is than showing researchers the logical and precise way in which innovation is generated? As a result of such an understanding, scientists would acquire, at a derisory cost—i.e., by merely recognizing the formalized logical possibility of breaking new ground or bringing about new arrangements-, a huge benefit, namely that of managing to critically examine their activities, along with their respective methods and material resources, thereby finding renewed avenues to engage in their R\&D areas, as well as to perform with a view to achieving innovative results. But is there a logical formula to innovate?

There is no reason not to begin by introducing something innovative to bring in the meaning of innovation. Take, as an example, the word "inno-duction." It is a very modest innovation, but also very simple and therefore prone to serve, with all due care, to the present purpose. After being decomposed, both "inno-vation" and "intro-duction" formed the word "innoduction."

\section{Development}

This could have been the first time ever that the word "innoduction" appeared. It certainly was not, as (Eekels 2000; Eekels 2001) and others, such as Amaresh Chakrabarti (' 2002), had already employed the word "innoduction," and did so in a far more significant way than that found above. They used the concept to refer to an alleged fourth sort of inference - that of innoduction, a logical formula for innovative thinking-beyond deduction, induction, and abduction. 
Three sorts of inference are known by tradition: deduction (i), induction (ii), and abduction (or hypothesis, iii). The following are illustrations of the three sorts of syllogism:

i) all the 'smiles' on the screen are 'emojis' and these 'smiles' are on the screen, so these 'smiles' are 'emojis;'

ii) these 'smiles' are 'emojis' and these 'smiles' are on the screen, so all the 'smiles' on the screen are 'emojis;'

iii) these 'smiles' are 'emojis' and all the 'smiles' on the screen are 'emojis,' so these 'smiles' are on the screen.

These (supra) are the three sorts of syllogism that we are all broadly conversant with. In deduction, conclusion has exact value, for it necessarily follows from the underlying assumptions. In induction, conclusion has probabilistic value, for it amplifies what would be the necessary conclusion of what would therefore be a deductive syllogism. For the example above (ii) to be a deduction, the conclusion would have to be that "at least some of the 'smiles' on the screen are 'emojis'."

Abduction, which may seem to the inattentive eye to be a mere case of "shooting in the dark," is logically worthwhile because it is not possible to "abduct" a fact without, invariably, facing two premises qualified to play the roles of conclusion and of one premise of that which would be-were the conclusion of the abduction the missing premise to complete the triad-a deductive syllogism. Thus, the conclusion of the abduction is a logically surprising fact, yet it does not constitute a logically inexplicable or ridiculous move.

As suggested by (Cramer-Petersen 2019), but few before Eekels have employed the term "innoduction," which perhaps was not forged yet in the early 1990s, when (Roozenburg 1993) established the distinction between "explanatory" and "innovative" abductive inferences or, in other words, abduction and innoduction.

Naming this document in such a way-though it is a fact that the employment of the word "innoduction" did not constitute, in itself, a lexicological sort of breakthrough-was instrumental in providing a rough representation of what is conventionally meant by innovation: bringing about new arrangements or breaking new ground.

There has not been a duplication of the finding of the word, let alone the concept of innoduction. But even if it involved a duplication, not of the innovation, of course, but rather of the discovery of the word, it should be noted that there is nothing to be discouraged about. When portraying scientific landscapes, room should be made for the wise guidance provided by (Ramón y Cajal 1999), who found it invaluable to run the risk of duplicating findings, rather than dropping all efforts to carry out further research.

In no rightful way can inquiry be blocked, whatever the degree of probability of confirming either this or that hypothesis, unless there is no longer any doubt. As (Peirce 1986) said in 1872, it 
is because uncertainty persists that the inquiry itself continues. By the time the doubts are dispelled, the inquiry can no longer last. In the Peircean sense, as (Deledalle 1990) taught, the "irritation of doubt" triggers thoughtfulness, but there is a chance to settle down and attain belief, meaning what puts a limit to doubt.

However, that is not the case here, because treating the subject of this essay continues to overload the mind with uncertainties, much beyond what would be reasonable in delineating a course of inquiry. Whenever this is so, the mind becomes apathetic or way too clingy, overburdened by the universe where it is in, and its snout can be seen guiding its wide-eyed gaze in the face of an empty, nude void, akin to that of Goya's Drowning Dog (Goya y Lucientes, n.d.).

\section{Conclusion}

The proposal here consisted only of the presentation of and commentary on the question about the existence of a logical formula for producing innovation. If such a formula, or innoductive syllogism, should prove to be effective, certainly it should be of the utmost concern for managers and researchers, just as for the overall population, to address it properly.

It could be that a community of researchers and managers aware of such a formula would be in a better position to produce and transmit the know-how about and based on such a formula, as well as to develop the appropriate expertise and flexibility to cope with a possibly disruptive impact on society at large, as a new age in the production of scientific and technological outputs would certainly be upon the horizon.

Consequently, a reality would have to be faced in which there would be no reason to seek hopelessly for innovative solutions to meet the scientific and societal challenges. Rather than trying to hit the target of innovation, managers and researchers in general would have to commit more diligently to the processes of harvesting, sorting, compiling, and commenting on the relevant resources, as well as to acquiring a sense of the value of these activities, to which others, such as translation and transliteration, could be appended.

Should a straightforward logical formula crack open the floodgates of a river brimming with innovative results, or should there be an explosion of innovation, there is no doubt that it would be needful to learn how to navigate the stormy waters that would be found in the science, technology and innovation ecosystem.

Likewise, it would be better to resist tempting and megalomaniac tendencies towards excessive aggregation of data and resources. This was a real challenge during the Renaissance, a time when researchers were looking to backup data, resulting in a growing datobesity throughout the period. Being aware of the loss of old works played a key role in determining the agenda of the Renaissance. Further and further available data streams signalled nothing but the pressing need to get to work. 
The urge to collect data certainly led people other than Theodor Zwinger, the editor of Theatrum Humanae Vitae, to launch themselves into frenzied ventures, to say the least. Still, such ventures could not be put down for free to the folly, obsession, or madness of some fools. In fact, as (Deuff 2018) said, the compilers felt comfortable in doing as they were doing. They believed that they were contributing to some common good.

It would certainly be challenging to manage a burst of innovation stemming from a generalized application of innoduction. However, is there really such a logical formula to break new paths?

\section{References}

Eekels, J. 2000. “On the Fundamentals of Engineering Design Science: The Geography of Engineering Design Science. Part 1". Journal of Engineering Design 11 (4): 377-97. https: //doi.org/10.1080/09544820010000962.

—. 2001. "On the Fundamentals of Engineering Design Science: The Geography of Engineering Design Science. Part 2”. Journal of Engineering Design 12 (3): 255-81. https: //doi.org/10.1080/09544820110055583.

'. 2002. Engineering Design Synthesis. Edited by Amaresh Chakrabarti. Springer London. https://doi.org/10.1007/978-1-4471-3717-7.

Cramer-Petersen, Claus L. 2019. "Reasoning Patterns in Team-Based Idea Generation". Ph.D., Lyngby: Technical University of Denmark.

Roozenburg, NFM. 1993. "On the Pattern of Reasoning in Innovative Design”. Design Studies 14 (1): 4-18. https://doi.org/10.1016/s0142-694x(05)80002-x.

Cajal, Santiago Ramón y. 1999. Advice for a Young Investigator. Translated by Neely Swanson and Larry W. Swanson. Cambridge, Mass: MIT Press.

Peirce, Charles S. 1986. Writings of Charles S. Peirce: A Chronological Edition, Volume 3: 1872-1878. Edited by Peirce Edition Project. Bloomington: Indiana University Press.

Deledalle, Gérard. 1990. Charles S. Peirce, 1839-1914: an Intellectual Biography. Amsterdam and Philadelphia: J. Benjamins Pub. Co.

Lucientes, Francisco de Goya y. n.d. "Perro Semihundido". https://www . goyaenelprado.es/obras/ficha/goya/perro-semihundido/?tx_

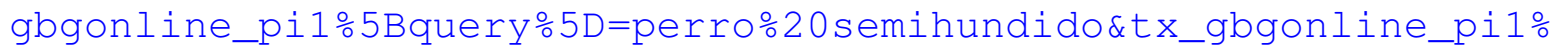
5Bgosort $\div 5 \mathrm{D}=\mathrm{b} \& \mathrm{tx}$ _gbgonline_pi1\%5Bgonavmode5D=search. https: //www.goyaenelprado.es/.

Deuff, Olivier Le. 2018. Digital Humanities. London and Hoboken, NJ: ISTE Ltd and John Wiley \& Sons, Inc. 